\title{
Preparation and structural determination of four metabolites of senkyunolide I in rats using ultra performance liquid chromatography/quadrupole-time-of-flight tandem mass and nuclear magnetic
} resonance spectra

\author{
Qiang $\mathrm{Ma}^{1}$, Cong Ma${ }^{1}$, Fei Wu' , Yao-kun Xiong ${ }^{2}$, Yi Feng ${ }^{1 *}$ and Shuang Liang ${ }^{1 *}$
}

\begin{abstract}
Background: Senkyunolide I (SEI) is one of the most important bioactive phthalides of Ligusticum chuanxiong Hort. (Umbelliferae), a Traditional Chinese Medicine. Our previous studies suggested that it might be developed as a potential treatment for migraine.

Methods: In this paper, we aimed to isolate and characterize the main metabolites of SEl after gavage feeding in rats. Their structures were identified precisely on the basis of nuclear magnetic resonance (NMR) spectroscopy and UPLC/QTOF-MS spectrometry. We also established the main metabolic pathways of SEl in rats.

Results: Four metabolites (M1-M4) were isolated, for the first time, from bile samples of rats by preparative high-performance liquid chromatography. Their structures were determined as SEI-6S-O- $\beta$-D-glucuronide (M1), SEl-7S-O- $\beta$-D-glucuronide (M2), SEl-7S-S-glutathione (M3) and SEl-7R-S-glutathione (M4) on the basis of the molecular mass of the analytes, using ultra performance liquid chromatography/quadrupole-time-of-flight mass spectrometry and $1 \mathrm{D}$ and $2 \mathrm{D}$ NMR.

Conclusions: The results demonstrated that glucuronide and glutathione conjugation were the major pathways of SEl metabolism in vivo, and the configuration at the 7th-position could be inverted during glutathione conjugation.
\end{abstract}

Keywords: Senkyunolide I, Metabolites, UPLC/Q-TOF-MS, NMR, In vivo

\section{Background}

Ligusticum chuanxiong Hort. (Umbelliferae) is a traditional Chinese herbal medicine that has been used to treat cardio- and cerebro-vascular disorders, such as angina pectoris, stroke and migraine, in China for thousands of years [1]. The chemistry and pharmacological effects of chuanxiong have been well documented.

\footnotetext{
*Correspondence: fyi_shutcm@163.com; Is7312@163.com

'Engineering Research Center of Modern Preparation of TCM, Ministry of Education, Shanghai University of Traditional Chinese Medicine, Room 5117 No. 1200 Cai Lun Road, Pudong District, Shanghai 201203, People's Republic of China

Full list of author information is available at the end of the article
}

Phthalides have been reported as the primary bioactive constituents in this herb. Various pharmacological activities of the main phthalides, such as ligustilide and senkyunolide $\mathrm{A}$, have been revealed, and their contributions to the beneficial effects of the herb are supported by in vivo and in vitro studies [2-5].

Senkyunolide I (SEI, Fig. 1), a representative metabolite of ligustilide in vivo and in vitro [6,7], is one of the most important bioactive constituents of chuanxiong $[6,8-11]$. Several studies have demonstrated that SEI could decrease hydrogen peroxide $\left(\mathrm{H}_{2} \mathrm{O}_{2}\right)$-induced oxidative damage in cultured human liver HepG2 cells [7] and PC12 cells [12]. SEI could also decrease the morphological 

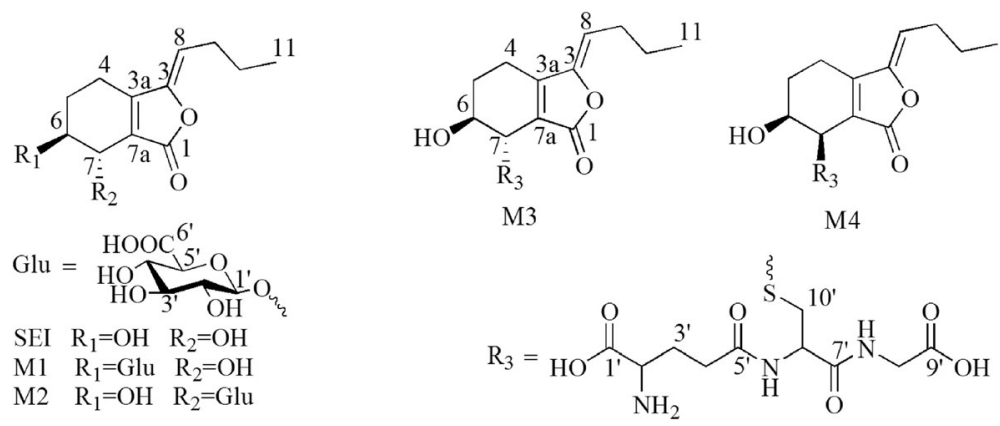

Fig. 1 Chemical structures of the SEl and its metabolites M1-M4

damage to red blood cells induced by concanavalin A [13]. Our previous study demonstrated that SEI could treat migraines, although the mechanism is unclear [14]. In addition, SEI is more stably in vitro, and has higher solubility $[15,16]$ and higher oral bioavailability $[17,18]$ compared with ligustilide and senkyunolide A. These properties of SEI suggest that it has a better potential as a new drug than ligustilide and senkyunolide A.

Generally, drug metabolism has a significant impact on the safety and efficacy of a drug and is commonly investigated at early stage of new drugs development. The identification of the drug's metabolites is indispensable in this process [19]. Liquid chromatography (LC) coupled with tandem mass spectrometry has become a powerful tool to study drug metabolism because of its superior sensitivity and specificity $[20,21]$. Quadrupoletime-of-flight mass spectrometry (Q/TOF-MS) is very useful in the characterization of drug metabolites because the technique provides accurate masses of ions and reveals valuable structural information [22]. In our previous study [23], 18 metabolites were characterized on the basis of ultra performance liquid chromatography/Q/TOF-MS (UPLC/Q-TOF-MS) analysis. However, because there are two chiral carbons (6-C and 7-C) in the molecular structure of SEI, the chemical structures of SEI conjugates present in vivo have not been fully characterized using Q/TOF-MS. To confirm further the structures of the main metabolites, and to obtain the pharmacological and toxicological information on them, it is essential to obtain adequate reference standards. Therefore, as part of our research on SEI, we aimed to isolate and characterize the metabolites of SEI, and to confirm the principal pathways of SEI metabolism in vivo.

In this study, four main metabolites were isolated from bile samples after gavage feeding of $100 \mathrm{mg} / \mathrm{kg}$ of SEI to rats. Their structures were identified precisely on the basis of nuclear magnetic resonance (NMR) and UPLC/ Q-TOF-MS spectra. We also established the main metabolic pathways of SEI in rats.

\section{Methods}

\section{Chemicals and reagents}

SEI (purity $>99.1 \%$, as tested by HPLC-UV) was obtained from $L$. chuanxiong extracts in our laboratory. Its structure was confirmed by comparison of its MS and NMR profiles with that published in the literature $[24,25]$. Slices of L. chuanxiong (No. 20130419) were purchased from Bozhou Medicinal Materials Company (Anhui Province, China) and authenticated by Professor Zhi-li Zhao of the Shanghai University of Traditional Chinese Medicine (Shanghai, China). The ultrahigh purified water used in this study was prepared in a Milli-Q water purification system (Millipore Corp., Billerica, MA, USA). Methanol and acetonitrile (HPLC grade) were purchased from Merck KGaA (Darmstadt, Germany). MeOH-d4, with tetramethylsilane (TMS) as internal standard for NMR analysis, was purchased from Cambridge Isotope Laboratories, Inc. (Andover, MS, USA). MCI Gel CHP 20P $(75 \mu \mathrm{m}-150 \mu \mathrm{m})$ for column chromatography was purchased from Mitsubishi (Tokyo, Japan). Sephadex LH-20 was obtained from GE Healthcare Bio-Sciences $\mathrm{AB}$ (Sweden). Other reagents and chemicals, including formic acid, were of analytical grade.

\section{Animals and drug administration}

Twenty-eight male Sprague-Dawley rats (275-300 g body weight) were provided by the Experimental Animal Centre, Shanghai University of Traditional Chinese Medicine, China. Animals were housed at an ambient temperature of $24 \pm 2{ }^{\circ} \mathrm{C}$ and $60 \pm 5 \%$ humidity, with a $12 \mathrm{~h}$ dark-light cycle. They were kept in an environmentally controlled breeding room and given tap water and fed ad libitum until $12 \mathrm{~h}$ before the experiment. Animal experimental procedures and welfare were strictly in accordance with the Guide for the Care and Use of Laboratory Animals and the related ethics regulations of Shanghai University of TCM. Our animal protocol was approved by the Institutional Animal Care and Use Committee, Shanghai University of TCM (Shanghai, China). SEI was dissolved in deionized water $(10 \mathrm{mg} \bullet \mathrm{ml}-1)$ 
and administered by gavage at a dose of $100 \mathrm{mg} \bullet \mathrm{kg}-1$ body weight.

\section{Samples collection and processing procedures}

The 28 rats were intraperitoneally injected with urethane $\left(1.0 \mathrm{~g} \cdot \mathrm{kg}^{-1}\right.$ body weight). Under anesthesia, a polyethylene cannula was inserted into the bile duct. Bile samples were collected for $12 \mathrm{~h}$ (approximately $400 \mathrm{~mL}$ in total) after oral administration of SEI at a dose of $100 \mathrm{mg} \cdot \mathrm{kg}^{-1}$ body weight. Blank rat bile was collected before oral administration. All the samples were stored at $-20{ }^{\circ} \mathrm{C}$ until further isolation and analysis.

Bile samples $(100 \mu \mathrm{L})$ for HPLC-UV analysis were mixed with $400 \mu \mathrm{L}$ of methanol for $60 \mathrm{~s}$. They were then centrifuged at 13,000 rpm for $10 \mathrm{~min}$, the supernatant was next transferred to a clear Eppendorf tube and then used $20 \mu \mathrm{Lwas}$ analysed using a HPLC-UV system.

\section{Isolation and purification of the metabolites of bile samples}

About $400 \mathrm{ml}$ of bile samples, which were centrifuged at 5,000 rpm for $10 \mathrm{~min}$ at $4{ }^{\circ} \mathrm{C}$ firstly, were subjected to MCI Gel CHP 20P column chromatography $(\Phi 4.5 \times 70 \mathrm{~cm})$ and eluted with a $\mathrm{MeOH}-\mathrm{H}_{2} \mathrm{O}$ stepwise gradient (0:100, 10:90; 20:80, 30:70, 45:55, 60:40, v/v). The metabolites were mainly obtained from the $10 \%, 20 \%$ and $30 \% \mathrm{MeOH}-\mathrm{H}_{2} \mathrm{O}$ fractions. The fractions were concentrated in vacuo to yield residues. The residues were dissolved in a small amount of $30 \% \mathrm{MeOH}-\mathrm{H}_{2} \mathrm{O}$, subjected to a Sephadex LH-20 column $(\Phi 2.5 \times 150 \mathrm{~cm})$ and eluted with $30 \% \mathrm{MeOH}-\mathrm{H}_{2} \mathrm{O}$. The metabolites were further purified by preparative HPLC, performed with an Agilent Zorbax Eclipse XDB-C18 $(5 \mu \mathrm{m}, 9.4 \times 250 \mathrm{~mm})$ at $30{ }^{\circ} \mathrm{C}$ in an Agilent 1200 HPLC system (Agilent Technologies, USA). The detection wavelength was set at $278 \mathrm{~nm}$. The mobile phase component $\mathrm{A}$ was water and $\mathrm{B}$ was acetonitrile, at a flow rate of $3 \mathrm{ml} \cdot \mathrm{min}^{-1}$, and the column was eluted with a linear gradient of $4-15 \%$ B over $0-15 \mathrm{~min}, 15-20 \%$ B over $15-42 \mathrm{~min}, 20-60 \%$ B over 42-44 min and finally, the column was reconditioned with $4 \%$ B for 4 min to give M1 (57 mg), M2 (68 mg), M3 (14 mg) and M4 (61 mg).

\section{HPLC-UV analysis conditions}

Analytical HPLC-UV analysis was carried out on an Agilent 1200 Series analytical HPLC system (Agilent Technologies, USA). A $20-\mu \mathrm{L}$ injection loop and a Grace C18 reversed-phase column $(5 \mu \mathrm{m}, 4.6 \times 150 \mathrm{~mm})$, protected by an Security Guard Cartridges C18 $(5 \mu \mathrm{m}, 4 \times 3.0 \mathrm{~mm})$ guard column, were used for analysis. The analytic HPLC conditions comprised: a flow rate of $1 \mathrm{~mL} \cdot \mathrm{min}^{-1}$; the mobile phase component A was water with $0.1 \%$ formic acid and B was acetonitrile; the column was eluted with a linear gradient of $4 \% \mathrm{~B}$ over $0-2 \mathrm{~min}, 4-8 \% \mathrm{~B}$ over
2-5 min, $8-28 \%$ B over $5-41 \mathrm{~min}, 28-4 \%$ B over $41-$ $43 \mathrm{~min}$ and the composition was maintained 4\% B for $2 \mathrm{~min}$. The detector wavelength was set at $278 \mathrm{~nm}$ and column temperature was maintained at $25^{\circ} \mathrm{C}$.

\section{Chromatographic and mass spectrometric conditions}

Chromatography was performed on an ACQUITY ${ }^{\mathrm{TM}}$ UPLC system (Waters Corp., Milford, MA, USA) with a conditioned auto sampler at $10{ }^{\circ} \mathrm{C}$. The chromatographic separation was carried out on an ACQUITY UPLC HSS T3 column $(1.8 \mu \mathrm{m}$, i.d. $2.1 \times 100 \mathrm{~mm})$. The column temperature was maintained at $45{ }^{\circ} \mathrm{C}$. The analysis was achieved with gradient elution using A (aqueous $0.1 \%$ formic acid) and B (acetonitrile) as the mobile phase. The gradient condition of the metabolites analysis was 0-15 min $20 \% \mathrm{~B}$. The injection volume was $5 \mu \mathrm{L}$. The electrospray ionization source was operated in positive ionization mode with the capillary voltage at $2.7 \mathrm{kV}$. The source and desolvation temperatures were set to $120{ }^{\circ} \mathrm{C}$ and $400{ }^{\circ} \mathrm{C}$, respectively. The cone gas flow was $50 \mathrm{~L} . \mathrm{h}^{-1}$ and the desolvation gas was set to $700 \mathrm{~L} / \mathrm{h}$.

\section{NMR spectroscopy}

A Broker AV 600 NMR spectrometer (Faellanden, Switzerland) was used to record $1 \mathrm{H}$ NMR $(600 \mathrm{MHz})$ and 13C NMR (125 MHz) spectra in C5D5N at $25{ }^{\circ} \mathrm{C}$. Chemical shifts were expressed in parts per million (ppm), with tetramethylsilane as the standard.

\section{Results}

\section{Isolation and identification of SEI metabolites}

As shown in Fig. 2, four main metabolites were found in bile samples of rats after oral administration of SEI, none of which had been isolated previously. The chemical structures of the metabolites were elucidated on the basis of UPLC/Q-TOF-MS and NMR spectra $\left({ }^{1} \mathrm{H}\right.$ NMR, $\left.{ }^{13} \mathrm{C} \mathrm{NMR}\right)$, heteronuclear single quantum coherence (HSQC) and the heteronuclear multiple-bond correlation (HMBC).

Careful analysis of the data collected from the UPLC/ Q-TOF-MS system resulted in the identification of four metabolites in rat bile (M1-M4). Their $[\mathrm{M}+\mathrm{H}]^{+}$ions were at $\mathrm{m} / \mathrm{z} 401.1455,401.1453,514.1870$ and 514.1874 for M1-M4, respectively (Fig. 3). The elemental compositions, experimental mass, calculated mass, double-bond equivalents (DBE) and the mass errors of the $[\mathrm{M}+\mathrm{H}]^{+}$ions are shown in Table 1 . The $\lambda$ max values observed in the UV spectra of these four metabolites were 274 (M1), 275 (M2), 278 (M3) and 277 (M4) nm, suggesting that the metabolites have similar chromophore frameworks to SEI. The structures of theses metabolites were further elucidated by NMR spectroscopy. Metabolites M1 and M2 were glucuronide conjugates, and the linkage positions 


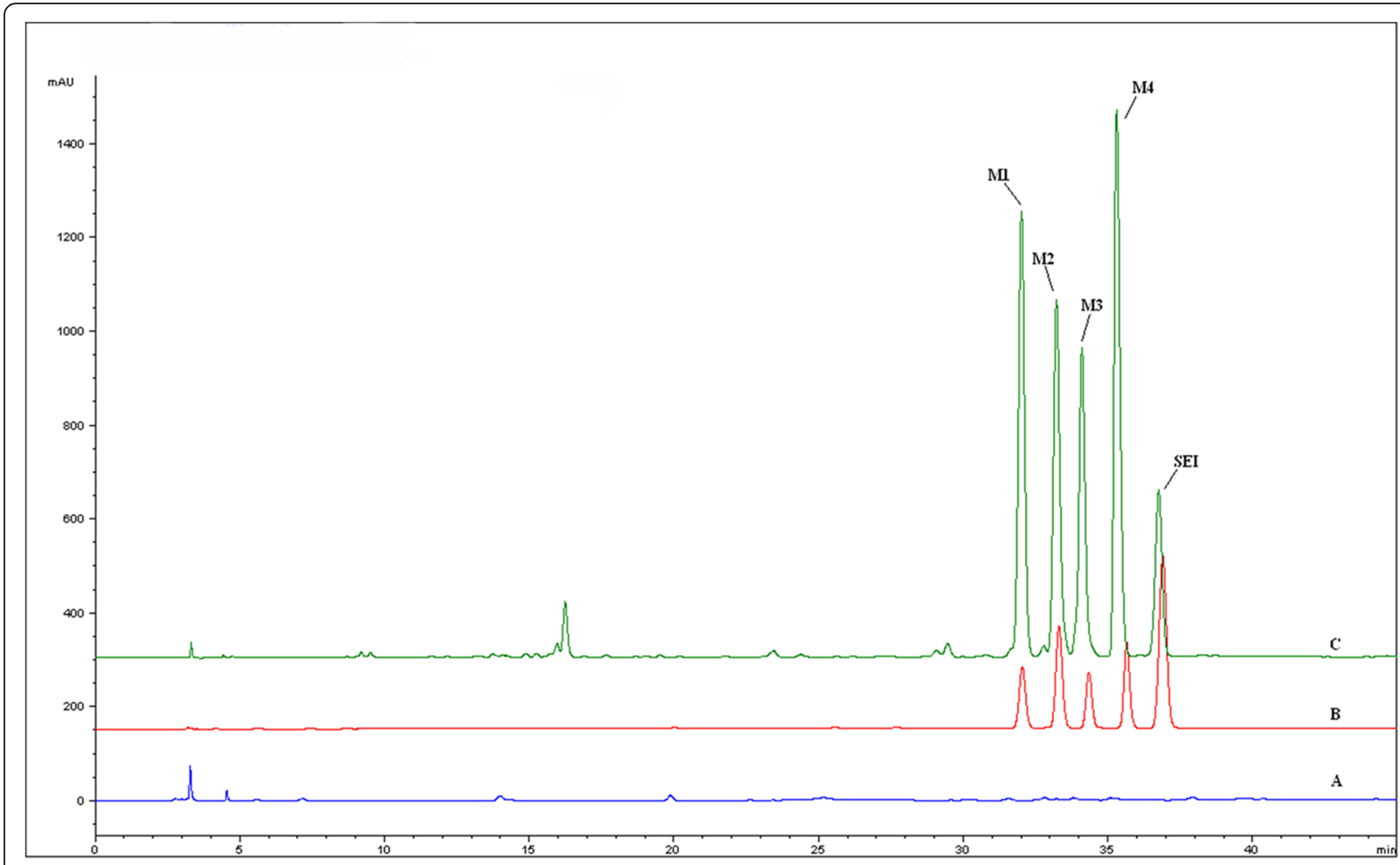

Fig. 2 Chromatograms for the analysis of the four metabolites of SEl in rat bile. (A) HPLC-UV chromatograms of control bile; (B) HPLC-UV chromatograms of M1-M4 and SEl standards without bile; (C) Bile samples from rats after oral administration $100 \mathrm{mg} / \mathrm{ml}$ of SEl

were at the 6- or 7-hydroxyl positions. For the glutathione conjugates metabolites M3 and M4, the linkage positions were at the 7-hydroxyl position, but they are cis-trans isomers of each other.

\section{Metabolites M1 and M2}

Metabolites M1 and M2 showed retention times of 4.18 and $4.70 \mathrm{~min}$ on the UPLC system (Fig. 4), with the same protonated molecular ion at $m / z$ 401. Q-TOF-MS

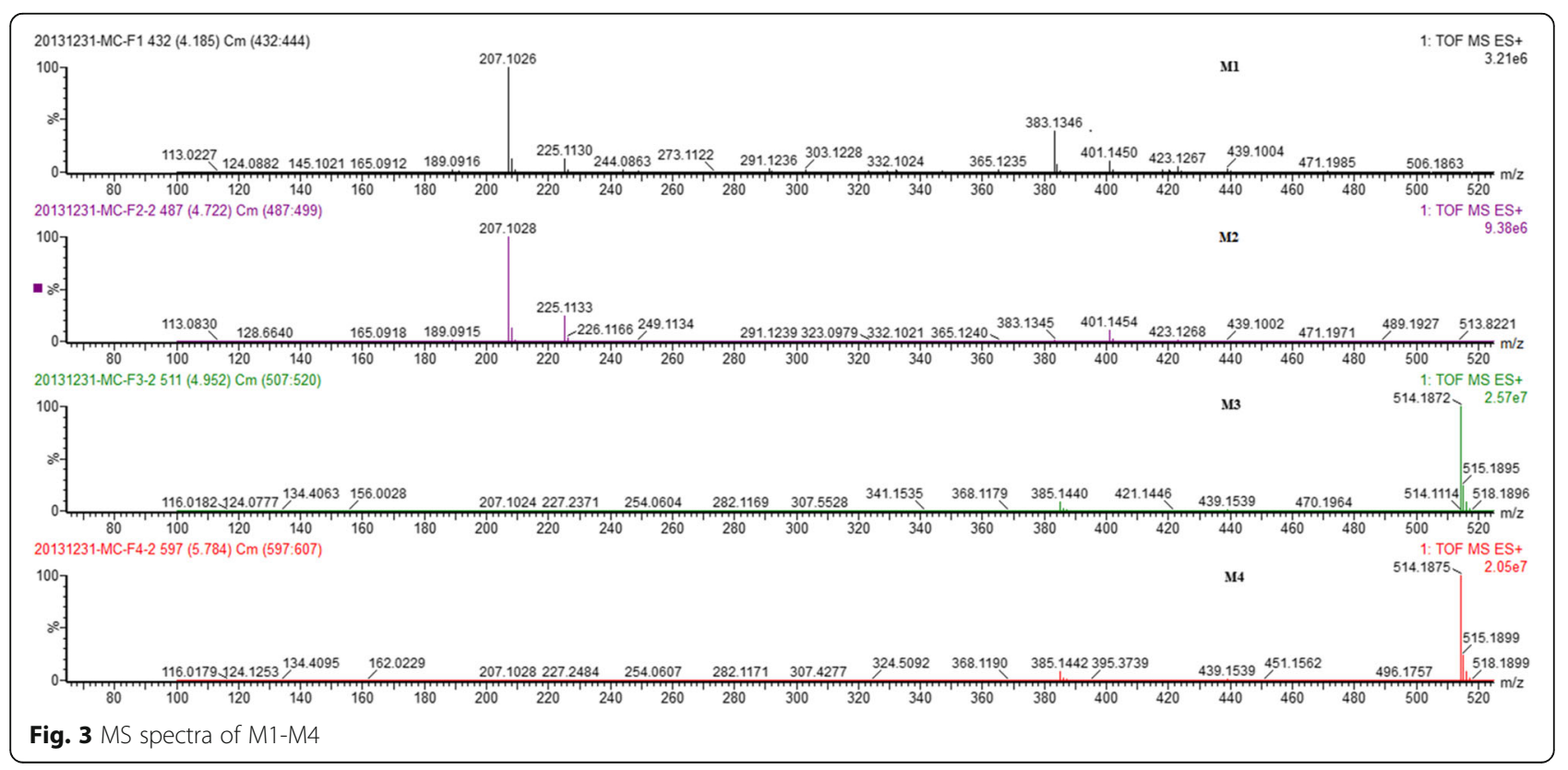


Table 1 The mass data for metabolites of Senkyunolide I (SEI)

\begin{tabular}{lccccccc}
\hline Compound & Observed mass $(\mathrm{Da})$ & Calculated mass $(\mathrm{Da})$ & Error $(\mathrm{mDa})$ & Error $(\mathrm{ppm})$ & DBE & Norm & Formula \\
\hline M1 & 401.1455 & 401.1448 & 0.6 & 1.5 & 6.5 & 0.048 & $\mathrm{C}_{18} \mathrm{H}_{25} \mathrm{O}_{10}$ \\
M2 & 401.1453 & 401.1448 & 0.7 & 1.7 & 6.5 & 0.004 & $\mathrm{C}_{18} \mathrm{H}_{25} \mathrm{O}_{10}$ \\
M3 & 514.1870 & 514.1859 & 1.4 & 2.7 & 8.5 & 2.062 & $\mathrm{C}_{22} \mathrm{H}_{32} \mathrm{~N}_{3} \mathrm{O}_{9} \mathrm{~S}$ \\
M4 & 514.1874 & 514.1859 & 1.5 & 2.9 & 8.5 & 1.554 & $\mathrm{C}_{22} \mathrm{H}_{32} \mathrm{~N}_{3} \mathrm{O}_{9} \mathrm{~S}$ \\
\hline
\end{tabular}

showed the protonated molecular ion at $\mathrm{m} / \mathrm{z} 401.1455$ (calculated 401.1448) for M1 and 401.1453 (calculated 401.1448) for M2, corresponding to the same molecular formula, $\mathrm{C}_{18} \mathrm{H}_{25} \mathrm{O}_{10}$. The molecular formulas of the two metabolites were further supported by the NMR spectral data.

The ${ }^{13} \mathrm{C}$ NMR data of M1 (Table 2) clearly showed the existence of a glucuronic acid unit $\left[\delta_{\mathrm{C}} 104.2\left(\mathrm{C}-1^{\prime}\right), 74.8\right.$ (C-2'), 77.9 (C-3'), 73.6 (C-4'), $76.4\left(\mathrm{C}-5^{\prime}\right)$ and 176.8 $\left(\mathrm{C}-6^{\prime}\right)$ ] [26]. It also showed signals from the butylidene side chain in the ${ }^{13} \mathrm{C}$ NMR data $\left[\delta_{\mathrm{C}} 114.4(\mathrm{C}-8), 29.0\right.$ (C-9), $23.3(\mathrm{C}-10)$ and $14.1(\mathrm{C}-11)]$ in the aglucon part of M1. The ${ }^{13} \mathrm{C}$ NMR spectra $\left[\delta_{\mathrm{C}} 170.8(\mathrm{C}-1)\right.$, 150 (C-3), 156.0 (C-3a) and 126.4 (C-7a)] certified a five membered lactone ring. Two oxygen-bearing carbon signals were observed at $\delta_{\mathrm{C}} 79.5(\mathrm{C}-6)$ and $63.5(\mathrm{C}-7)$, which were both tertiary carbons and the vicinal hydroxymethine protons appeared at $\delta_{\mathrm{H}} 4.07(\mathrm{~m})$ and 4.46 $(\mathrm{d}, J=3.3 \mathrm{~Hz})$. All the NMR spectra of M1 were similar to those of SEI [24, 25], except for the additional glucuronic acid unit. In our previous study [23], we noted that glucuronidation was one of the major metabolic pathways of SEI in vivo, and the structure this metabolite was elucidated as SEI-6S-O$\beta$-D-glucuronide or SEI-7S-O- $\beta$-D-glucuronide. In the present study, there was a long-range correlation between $\mathrm{H}-6\left(\delta_{\mathrm{H}} 4.07, \mathrm{~m}\right)$ and $\mathrm{C}^{-1}{ }^{\prime}\left(\delta_{\mathrm{C}}\right.$ 79.5) in HMBC spectrum (Table 2). Thus, the structure of M1 was definitively identified as SEI-6S-O- $\beta$-D-glucuronide with the help of 2D-NMR.

The ${ }^{13} \mathrm{C}$ NMR data of M2 (Table 2) also clearly showed the existence of a glucuronic acid moiety $\left[\delta_{\mathrm{C}}\right.$ 104.7 (C-1'), 75.1 (C-2'), 77.8 (C-3'), 73.6 (C-4'), 75.8 $\left(\mathrm{C}-5^{\prime}\right)$ and $\left.176.8\left(\mathrm{C}-6^{\prime}\right)\right]$. The ${ }^{13} \mathrm{C}$ NMR data of the aglycone part of M2 (Table 2) were similar to those of M1 (Table 2), except for the carbon signals of C-6 $\left(\delta_{\mathrm{C}} 70.2\right)$ and $\mathrm{C}-7\left(\delta_{\mathrm{C}} 74.9\right)$, which were different from those of M1. Based on the cross peak between C-1' $\left(\delta_{\mathrm{C}} 104.7\right)$ and $\mathrm{H}-7\left(\delta_{\mathrm{H}} 4.44, \mathrm{~d}, J=3.9 \mathrm{~Hz}\right)$ in the $\mathrm{HMBC}$ spectrum, the structure of M2 was elucidated as SEI-7S-O- $\beta$-Dglucuronide.

\section{Metabolites M3 and M4}

Metabolites M3 and M4 showed retention times of 4.94 and $5.77 \mathrm{~min}$ on the UPLC system (Fig. 4), with the same protonated molecular ion at $m / z 514$. Q-TOF-MS showed the protonated molecular ion at $\mathrm{m} / z 514.1870$ (calculated 514.1859) for M3 and 514.1874 (calculated 514.1859) for M4, corresponding to the same molecular

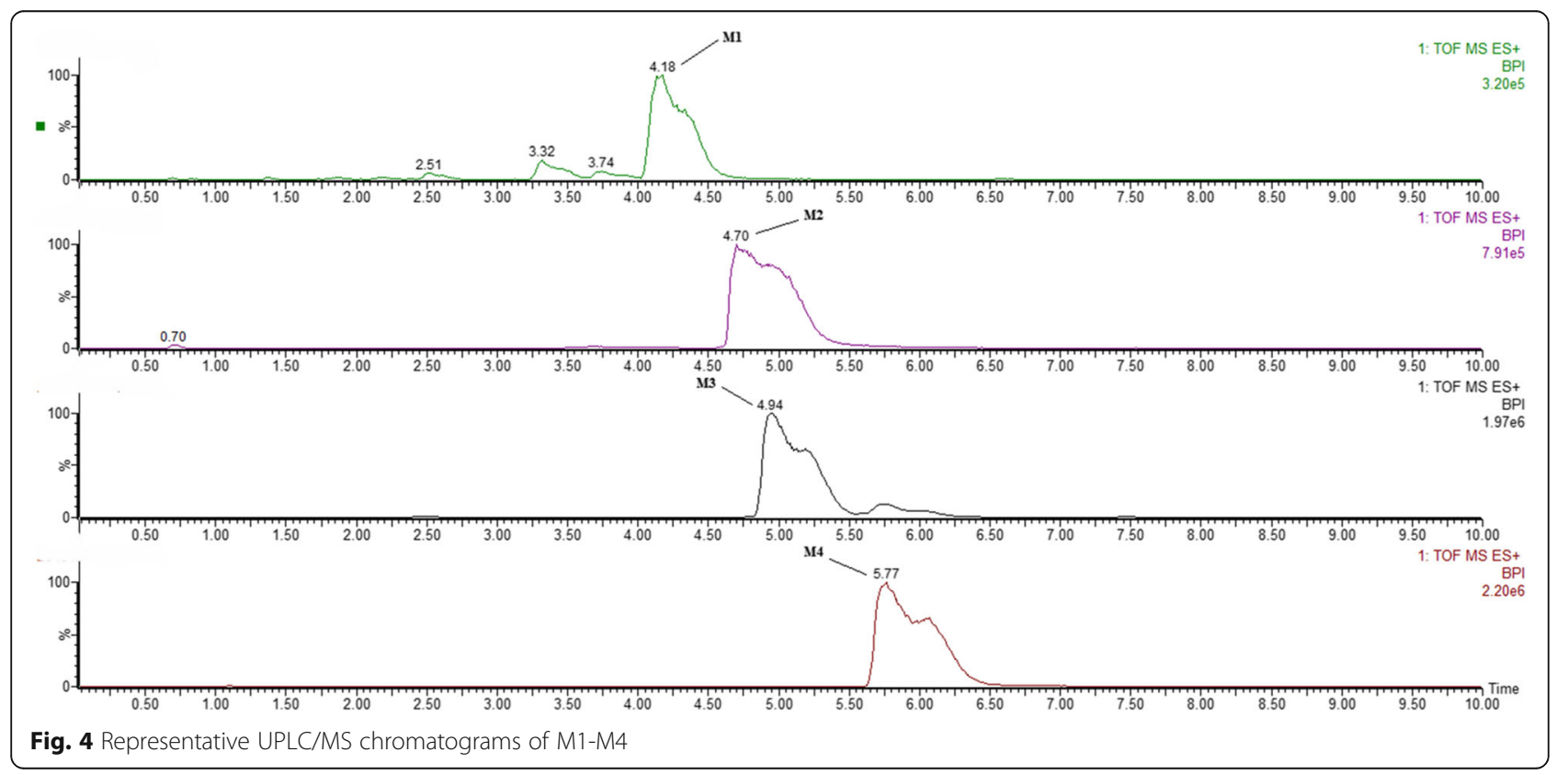


Table 2 1D and 2D nuclear magenetic resonance (NMR) data of metabolites M1 and M2. ( $\delta$ in ppm, MeOH- $\left.d_{4}\right)$

\begin{tabular}{|c|c|c|c|c|c|c|}
\hline \multicolumn{2}{|c|}{ Position } & \multicolumn{2}{|l|}{ M1 } & \multicolumn{3}{|l|}{$\mathrm{M} 2$} \\
\hline & $\delta_{C}$ & $\delta_{H}$ & $\mathrm{HMBC}$ & $\delta_{C}$ & $\delta_{H}$ & $\mathrm{HMBC}$ \\
\hline 1 & 170.8 & - & - & 171.0 & - & - \\
\hline 3 & 150.0 & - & - & 150.0 & - & - \\
\hline $3 a$ & 156.0 & - & - & 156.1 & - & - \\
\hline \multirow[t]{2}{*}{4} & 18.7 & $2.48(1 \mathrm{H}, \mathrm{ddd}, J=18.7,5.6,3.4 \mathrm{~Hz})$ & $C-5,6,7 a$ & 18.8 & $2.53(2 \mathrm{H}, \mathrm{m})$ & $C-3 a, 5,6,7 a$ \\
\hline & & $2.67(1 \mathrm{H}, \mathrm{ddd}, J=18.2,9.5,5.8 \mathrm{~Hz})$ & $C-3 a, 5,6,7 a$ & & & \\
\hline \multirow[t]{2}{*}{5} & 24.3 & $2.01(1 \mathrm{H}, \mathrm{m})$ & $C-3 a, 4$ & 26.2 & $1.90(1 \mathrm{H}, \mathrm{m})$ & $C-3 a, 4,6,7$ \\
\hline & & $2.18(1 \mathrm{H}, \mathrm{ddd}, J=14.0,8.9,5.4 \mathrm{~Hz})$ & $C-3 a, 4,6,7$ & & $2.01(1 \mathrm{H}, \mathrm{dt}, J=13.7,5.7 \mathrm{~Hz})$ & $C-3 a, 4,6,7$ \\
\hline 6 & 79.5 & $4.07(1 \mathrm{H}, \mathrm{m})$ & $C-4,7,7 a, 1^{\prime}$ & 70.2 & $4.13(1 \mathrm{H}, \mathrm{m})$ & $C-4,5,7,7 a$ \\
\hline 7 & 63.5 & $4.46(1 \mathrm{H}, \mathrm{d}, J=3.3 \mathrm{~Hz})$ & $C-1,3 a, 5,6,7 a$ & 74.9 & $4.44(1 \mathrm{H}, \mathrm{d}, J=3.9 \mathrm{~Hz})$ & $C-1,3 a, 5,6,7 a, 1^{\prime}$ \\
\hline $7 a$ & 126.4 & - & - & 125.3 & - & - \\
\hline 8 & 114.4 & $5.45(1 \mathrm{H}, \mathrm{t}, J=7.9 \mathrm{~Hz})$ & $C-3,3 a, 9,10$ & 115.2 & $5.48(1 \mathrm{H}, \mathrm{t}, J=7.9 \mathrm{~Hz})$ & $C-3,3 a, 10$ \\
\hline 9 & 29.0 & $2.34(2 \mathrm{H}, \mathrm{dd}, J=15.0,7.6 \mathrm{~Hz})$ & $C-3,8,10,11$ & 29.1 & $2.34(2 \mathrm{H}, \mathrm{dd}, J=15.0,7.5 \mathrm{~Hz})$ & $C-3,8,10,11$ \\
\hline 10 & 23.3 & $1.51(2 \mathrm{H}, \mathrm{m})$ & $C-8,9,11$ & 23.3 & $1.52(2 \mathrm{H}, \mathrm{dt}, J=14.7,7.3 \mathrm{~Hz})$ & $C-8,9,11$ \\
\hline 11 & 14.1 & $0.96(3 \mathrm{H}, \mathrm{t}, J=7.4 \mathrm{~Hz})$ & $C-9,10$ & 14.1 & $0.95(3 \mathrm{H}, \mathrm{t}, J=7.4 \mathrm{~Hz})$ & $C-9,10$ \\
\hline $1^{\prime}$ & 104.2 & $4.46(1 \mathrm{H}, \mathrm{d}, J=7.8 \mathrm{~Hz})$ & $C-3^{\prime}, 5^{\prime}$ & 104.7 & $4.68(1 \mathrm{H}, \mathrm{d}, J=7.8 \mathrm{~Hz})$ & $C-7$ \\
\hline $2^{\prime}$ & 74.8 & $3.14(1 \mathrm{H}, \mathrm{t}, J=8.3 \mathrm{~Hz})$ & $C-1^{\prime}, 3^{\prime}$ & 75.1 & $3.20(1 \mathrm{H}, \mathrm{t}, J=8.4 \mathrm{~Hz})$ & $C-1^{\prime}, 3^{\prime}$ \\
\hline $3^{\prime}$ & 77.9 & $3.38(1 \mathrm{H}, \mathrm{t}, J=8.9 \mathrm{~Hz})$ & $C-2^{\prime}, 4^{\prime}$ & 77.8 & $3.42(1 \mathrm{H}, \mathrm{t}, J=6.0 \mathrm{~Hz})$ & $C-4^{\prime}$ \\
\hline $4^{\prime}$ & 73.6 & $3.41(1 \mathrm{H}, \mathrm{t}, J=9.1 \mathrm{~Hz})$ & $C-3^{\prime}, 6^{\prime}$ & 73.6 & $3.44(1 \mathrm{H}, \mathrm{t}, J=5.8 \mathrm{~Hz})$ & $C-3^{\prime}, 6^{\prime}$ \\
\hline $5^{\prime}$ & 76.4 & $3.57(1 \mathrm{H}, \mathrm{d}, J=9.4 \mathrm{~Hz})$ & $C-1^{\prime}, 3^{\prime}, 4^{\prime}, 6^{\prime}$ & 75.8 & $3.63(1 \mathrm{H}, \mathrm{m})$ & $C-1^{\prime}, 3^{\prime}, 4^{\prime}, 6^{\prime}$ \\
\hline $6^{\prime}$ & 176.8 & - & - & 176.8 & - & - \\
\hline
\end{tabular}

formula, $\mathrm{C}_{22} \mathrm{H}_{32} \mathrm{~N}_{3} \mathrm{O}_{9} \mathrm{~S}$. The molecular formulae of the two metabolites were further supported by the NMR spectral data.

The assignments of all the proton and carbon signals for M3 and M4 were achieved by $1 \mathrm{D}$ and 2D NMR experiments, and the data are listed in Table 3. The ${ }^{13} \mathrm{C}$ NMR data of M3 clearly showed a glutathione unit $\left[\delta_{\mathrm{C}} 174.2\left(\mathrm{C}-1^{\prime}\right), 55.8\left(\mathrm{C}-2^{\prime}\right), 33.3\left(\mathrm{C}-3^{\prime}\right), 27.8\right.$ (C-4'), $175.6\left(\mathrm{C}-5^{\prime}\right), 55\left(\mathrm{C}-6^{\prime}\right), 172.3\left(\mathrm{C}-7^{\prime}\right), 44.6\left(\mathrm{C}-8^{\prime}\right)$, $176.1\left(\mathrm{C}-9^{\prime}\right)$ and $36.7\left(\mathrm{C}-10^{\prime}\right)$ ] [27]. The NMR data of the other $\mathrm{C}$ atoms suggested that M3 has the same parent construction as M1 and M2. In our previous study [23], we also observed that glutathione conjugation was one of the metabolic pathways of SEI in vivo. The HMBC spectra showed cross peaks between $\mathrm{C}-10^{\prime}\left(\delta_{\mathrm{C}} 36.7\right)$ and $\mathrm{H}-7$ $\left(\delta_{\mathrm{H}} 3.86, \mathrm{~d}, J=3.3 \mathrm{~Hz}\right)$. Thus, M3 was characterized as SEI-7S-S-glutathione.

The ${ }^{1} \mathrm{H}$ NMR and ${ }^{13} \mathrm{C}$ NMR data of M4 were similar to those of $\mathrm{M} 3$, and the same planar structure as that of M3 was deduced from the HSQC and HMBC data of M4, which suggested that M4 is a diastereoisomer of M3. In the ${ }^{1} \mathrm{H}$ NMR, the $\mathrm{H}-7$ of $\mathrm{M} 4\left(\delta_{\mathrm{H}} 3.59, \mathrm{~s}\right)$ was a single peak, different from $\mathrm{H}-7\left(\delta_{\mathrm{H}} 3.86, \mathrm{~d}, J=3.6 \mathrm{~Hz}\right)$ in M3, which suggested that M4 is in the 6, 7-cisconfiguration [28]. Thus, the configurations of the 7- substituted groups were inverted during the metabolic process, and M4 was identified as SEI-7R-S-glutathione.

\section{Discussion}

In our previous study [18], SEI was rapidly absorbed and exhibited extensive distribution after oral administration. Its oral bioavailability was approximately $37.25 \%$, but it was quickly eliminated from plasma, with a half life of less than $60 \mathrm{~min}$. In a second metabolic experiment [23], the biotransformation of SEI was investigated using UPLC/Q-TOF-MS. Eighteen metabolites were identified and the result indicated that methylation, hydration, epoxidation, glucuronidation and glutathione conjugation were the major pathways of SEI metabolism in vivo. Based on the results above, the fast elimination from plasma could be explained by rapid and extensive metabolism. However, the chemical structures of SEI conjugates present in vivo have not been fully characterized.

In the present study, for the four main metabolites in bile samples, an elementary conclusion could be gained by analyzing the height and area of the peaks in HPLCUV chromatograms. It suggested that SEI-6S-O- $\beta$-Dglucuronide (M1), SEI-7S-O- $\beta$-D-glucuronide (M2), SEI7S-S-glutathione (M3) and SEI-7R-S-glutathione (M4) 
Table $31 \mathrm{D}$ and 2D nuclear magenetic resonance (NMR) data of metabolites M3 and M4. ( $\delta$ in ppm, MeOH- $\left.d_{4}\right)$

\begin{tabular}{|c|c|c|c|c|c|c|}
\hline \multicolumn{2}{|c|}{ Position } & \multicolumn{2}{|l|}{ M3 } & \multicolumn{3}{|l|}{ M4 } \\
\hline & $\delta_{c}$ & $\delta_{H}$ & $\mathrm{HMBC}$ & $\delta_{C}$ & $\delta_{H}$ & $\mathrm{HMBC}$ \\
\hline 1 & 169.9 & - & - & 170.8 & - & - \\
\hline 3 & 149.7 & - & - & 150.0 & - & - \\
\hline $3 a$ & 152.9 & - & - & 153.4 & - & - \\
\hline \multirow[t]{2}{*}{4} & \multirow[t]{2}{*}{21.2} & $2.46(1 \mathrm{H}, \mathrm{m})$ & C-3a, 5, 6, 7a & \multirow[t]{2}{*}{17.4} & $2.46(1 \mathrm{H}, \mathrm{m})$ & $C-3 a, 5,6,7 a$ \\
\hline & & $2.57(1 \mathrm{H}, \mathrm{m})$ & $C-3 a, 6,7 a$ & & $2.50(1 \mathrm{H}, \mathrm{m})$ & $C-3 a, 5,7 a$ \\
\hline 5 & 26.9 & $1.94(2 \mathrm{H}, \mathrm{m})$ & $C-3 a, 4,6,7$ & 24.6 & $1.95(2 \mathrm{H}, \mathrm{m})$ & $C-3 a, 4,6,7$ \\
\hline 6 & 70.3 & $4.08(1 \mathrm{H}, \mathrm{dt}, J=11.2,3.6 \mathrm{~Hz})$ & $C-4,5,7$ & 70.0 & $4.17(1 \mathrm{H}, \mathrm{m})$ & $C-4,7 a$ \\
\hline 7 & 45.4 & $3.86(1 \mathrm{H}, \mathrm{d}, J=3.8 \mathrm{~Hz})$ & $C-1,3 a, 5,6,7 a, 10^{\prime}$ & 43.1 & $3.59(1 \mathrm{H}, \mathrm{s})$ & $C-1,3 a, 5,6,7 a, 10^{\prime}$ \\
\hline $7 a$ & 127.3 & - & - & 125.7 & - & - \\
\hline 8 & 114.5 & $5.37(1 \mathrm{H}, \mathrm{t}, J=7.9 \mathrm{~Hz})$ & $C-3,3 a, 10$ & 114.2 & $5.40(1 \mathrm{H}, \mathrm{t}, J=7.9 \mathrm{~Hz})$ & $C-3,3 a, 10$ \\
\hline 9 & 29.1 & $2.29(2 \mathrm{H}, \mathrm{dd}, J=15.0,7.6 \mathrm{~Hz})$ & $C-3,8,10,11$ & 29.0 & $2.31(2 \mathrm{H}, \mathrm{dd}, J=15.0,7.5 \mathrm{~Hz})$ & $C-3,8,10,11$ \\
\hline 10 & 23.3 & $1.48(2 \mathrm{H}, \mathrm{dd}, J=14.7,7.4 \mathrm{~Hz})$ & $C-8,9,11$ & 23.3 & $1.48(2 \mathrm{H}, \mathrm{m})$ & $C-8,9,11$ \\
\hline 11 & 14.1 & $0.93(3 \mathrm{H}, \mathrm{m})$ & $C-9,10$ & 14.1 & $0.93(3 \mathrm{H}, \mathrm{t}, J=7.4 \mathrm{~Hz})$ & $C-9,10$ \\
\hline $1^{\prime}$ & 174.2 & - & - & 174.5 & - & - \\
\hline $2^{\prime}$ & 55.8 & $3.63(1 \mathrm{H}, \mathrm{m})$ & $C-1^{\prime}, 3^{\prime}, 5^{\prime}$ & 55.7 & $3.63(1 \mathrm{H}, \mathrm{t}, J=6 \mathrm{~Hz})$ & $C-1^{\prime}, 3^{\prime}, 5^{\prime}$ \\
\hline $3^{\prime}$ & 33.3 & $2.60(2 \mathrm{H}, \mathrm{m})$ & $C-2^{\prime}, 4^{\prime}, 5^{\prime}$ & 33.2 & $2.54(2 \mathrm{H}, \mathrm{m})$ & $C-2^{\prime}, 4^{\prime}, 5^{\prime}$ \\
\hline $4^{\prime}$ & 27.8 & $2.15(2 \mathrm{H}, \mathrm{dt}, J=14.3,7.3 \mathrm{~Hz})$ & $C-2^{\prime}, 3^{\prime}, 5^{\prime}$ & 28.0 & $2.13(2 \mathrm{H}, \mathrm{m})$ & $C-2^{\prime}, 3^{\prime}, 5^{\prime}$ \\
\hline $5^{\prime}$ & 175.6 & - & - & 175.4 & - & - \\
\hline $6^{\prime}$ & 55.0 & $4.67(1 \mathrm{H}, \mathrm{m})$ & $C-5^{\prime}, 7^{\prime}, 10^{\prime}$ & 55.0 & $4.66(1, m)$ & $C-5^{\prime}, 7^{\prime}, 10^{\prime}$ \\
\hline $7^{\prime}$ & 172.3 & - & - & 172.2 & - & - \\
\hline \multirow[t]{2}{*}{$8^{\prime}$} & \multirow[t]{2}{*}{44.6} & \multirow[t]{2}{*}{$3.72(2 \mathrm{H}, \mathrm{s})$} & \multirow[t]{2}{*}{$C-7^{\prime}, 9^{\prime}$} & \multirow[t]{2}{*}{44.7} & $3.69(1 \mathrm{H}, \mathrm{d}, J=17.1 \mathrm{~Hz})$ & $C-7^{\prime}, 9^{\prime}$ \\
\hline & & & & & $3.77(1 \mathrm{H}, \mathrm{d}, J=17.1 \mathrm{~Hz})$ & $C-7^{\prime}, 9^{\prime}$ \\
\hline $9^{\prime}$ & 176.1 & - & - & 176.4 & - & - \\
\hline \multirow[t]{2}{*}{$10^{\prime}$} & \multirow[t]{2}{*}{36.7} & $3.12(1 \mathrm{H}, \mathrm{dd}, J=14.2,7.7 \mathrm{~Hz})$ & $C-7,6^{\prime}, 7^{\prime}$ & \multirow[t]{2}{*}{35.7} & $3.00(1 \mathrm{H}, \mathrm{dd}, J=13.9,8.4 \mathrm{~Hz})$ & $C-7,6^{\prime}, 7^{\prime}$ \\
\hline & & $3.22(1 \mathrm{H}, \mathrm{dd}, J=14.1,5.0 \mathrm{~Hz})$ & $C-7,6^{\prime}, 7^{\prime}$ & & $3.22(1 \mathrm{H}, \mathrm{dd}, J=13.9,5.3 \mathrm{~Hz})$ & $C-7,7^{\prime}$ \\
\hline
\end{tabular}

were the major metabolites in vivo. In our experiment, only trace metabolites of SEI were determined in the urine of rats, all of which suggested that the final excretion pathway in rats was bile. The metabolic pathways of SEI in rat bile mainly involved glucuronidation and glutathione conjugation during the phase II biotransformation pathway in rats because of the 6- and 7-hydroxyl groups in its structure, and the configurations of 7-substituted groups may be inverted during glutathione conjugation. Based on the structures of these metabolites, the proposed metabolic pathways of SEI are shown in Fig. 5.

Glutathione plays an important role in maintaining the redox state of cells via scavenging reactive oxygen species. Glutathione conjugation of xenobiotics is a detoxification pathway that inactivates electrophiles, which may covalently bind to endogenous proteins, resulting in potential detrimental effects [29]. This metabolic mechanism of SEI is indicated for its toxicity, and further work is needed to clarify the potential toxicity of SEI. In theory, medicines or metabolites are supposed to be excreted ultimately out of the body via faeces after bile excretion. However, we did not detect any metabolites, except for SEI, in fecal samples. Therefore, we suspect that the toxicity might be derived from its metabolites to a great extent. There are a few examples where phase II metabolism will produce significantly more biologically active or more toxic metabolites, including morphine [30] and certain heterocyclic aromatic amine compounds [31, 32]. In this study, we identified only four main metabolites of SEI in vivo and further research will be carried out to identify other metabolites. Issues to be addressed comprise structure-activity relationship analysis, bioactivity evaluation, and the quantitative mass balance of these metabolites.

\section{Conclusions}

Our results demonstrated that glucuronide and glutathione conjugation are the major pathways of SEI metabolism in 


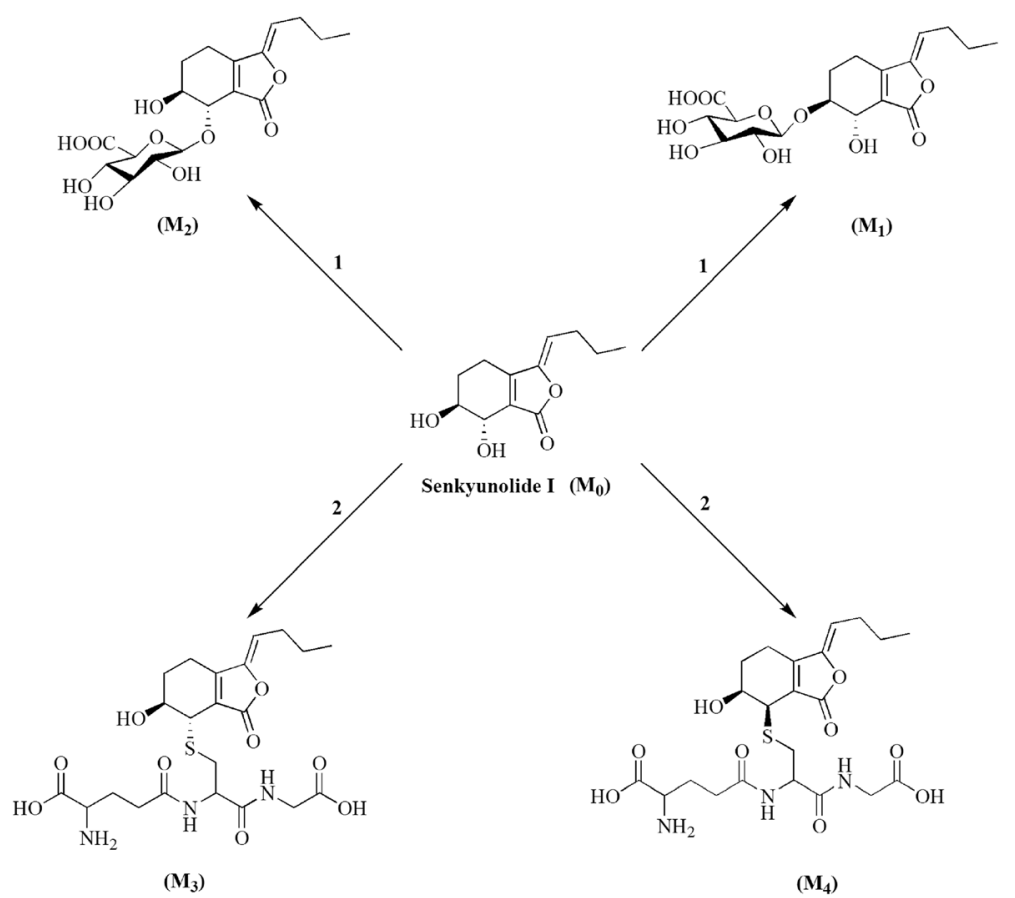

Fig. 5 The major metabolic pathways of SEl in rat bile samples after oral administration of $100 \mathrm{mg} / \mathrm{kg} \mathrm{SEl}$, including glucuronidation (1) and glutathione conjugation (2)

vivo, and the configuration at the 7th-position could be inverted during glutathione conjugation.

\section{Abbreviations}

DBE: Double-bond equivalents; HMBC: Heteronuclear multiple-bond correlation; HSQC: Heteronuclear single quantum coherence; LC: Liquid chromatography; NMR: Nuclear magnetic resonance; Q/TOF-MS: Quadrupoletime-of-flight mass spectrometry; SEl: Senkyunolide l; TMS: Tetramethylsilane; UPLC/Q-TOF-MS: Ultra performance liquid chromatography/Q/TOF-MS

\section{Acknowledgments}

We would like to thank Dr. C.Y. He and X. Lin for their excellent assistance of this study.

\section{Funding}

The work was supported by the funds from Shanghai Municipal Commission of Health and Family Planning (ZY3-CCCX-3-5001) and Science and Technology Commission of Shanghai Municipality (15DZ2292000).

\section{Availability of data and materials}

The datasets supporting the conclusions of this article are included within the article.

\section{Authors' contributions}

All authors participated in the conception and design of this research; QM and $\mathrm{CM}$ carried out the experiments, the data analysis and wrote the first draft of the manuscript; FW contributed to the acquisition and interpretation of data; YKX coordinated the study; YF and SL supervised the work and reviewed the final draft of the manuscript. All authors read and approved the final manuscript.

\section{Competing interests}

The authors declare that they have no competing interests.

\section{Consent for publication}

Not applicable.
Ethics approval and consent to participate

All the procedures were conducted in strict accordance with the PR China legislation on the use and care of laboratory animals, and with the guidelines established by the Institute for Experimental Animals of Shanghai University of TCM, and were approved by the university ethical committee for animal experiments.

\section{Author details}

${ }^{1}$ Engineering Research Center of Modern Preparation of TCM, Ministry of Education, Shanghai University of Traditional Chinese Medicine, Room 5117, No. 1200 Cai Lun Road, Pudong District, Shanghai 201203, People's Republic of China. ${ }^{2}$ Key Laboratory of Modern Preparation of TCM, Ministry of Education, Jiangxi University of Traditional Chinese Medicine, Nanchang 330004, People's Republic of China.

Received: 22 July 2016 Accepted: 18 November 2016 Published online: 05 December 2016

\section{References}

1. Pharmacopoeia NCoC. Pharmacopoeia of the People's Republic of China. Beijing: Chemical Industry Press; 2015.

2. HZ Z, ZH D, J S. Modern Study of Traditional Chinese Medicine. Beijing: Xueyuan Press; 1997.

3. Chan SS, Choi AO, Jones RL, Lin G. Mechanisms underlying the vasorelaxing effects of butylidenephthalide, an active constituent of Ligusticum chuanxiong, in rat isolated aorta. Eur J Pharmacol. 2006;537(1-3):111-7.

4. Chan SS, Cheng TY, Lin G. Relaxation effects of ligustilide and senkyunolide A, two main constituents of Ligusticum chuanxiong, in rat isolated aorta. J Ethnopharmacol. 2007;111(3):677-80.

5. Chan SK, Li SL, Lin G. Pitfalls of the selection of chemical markers for the quality control of medicinal herbs. J Food Drug Anal. 2007;15(4):365-71.

6. Yan R, Ko NL, Li SL, Tam YK, Lin G. Pharmacokinetics and metabolism of ligustilide, a major bioactive component in Rhizoma Chuanxiong, in the rat. Drug metabolism and disposition: the biological fate of chemicals. 2008; 36(2):400-8.

7. Tang J, Chen C, Yu Y, Du JR, Yang W, Wang CY. Pharmacological activities of Z-ligustilide and metabolites in rats. Sichuan da xue xue bao Yi xue ban = Journal of Sichuan University Medical science edition. 2009;40(5):839-42. 
8. Li SL, Chan SS, Lin G, Ling L, Yan R, Chung HS, Tam YK. Simultaneous analysis of seventeen chemical ingredients of Ligusticum chuanxiong by on-line high performance liquid chromatography-diode array detector-mass spectrometry. Planta Med. 2003:69(5):445-51.

9. Li SL, Lin G, Tam YK. Time-course accumulation of main bioactive components in the rhizome of Ligusticum chuanxiong. Planta Med. 2006; 72(3):278-80.

10. Ding C, Sheng Y, Zhang Y, Zhang J, Du G. Identification and comparison of metabolites after oral administration of essential oil of Ligusticum chuanxiong or its major constituent ligustilide in rats. Planta Med. 2008;74(14):1684-92.

11. Zuo A, Wang L, Xiao H, Li L, Liu Y, Yi J. Identification of the absorbed components and metabolites in rat plasma after oral administration of Rhizoma Chuanxiong decoction by HPLC-ESI-MS/MS. J Pharm Biomed Anal. 2011;56(5):1046-56.

12. Qi H, Siu SO, Chen Y, Han Y, Chu IK, Tong Y, Lau AS, Rong J. Senkyunolides reduce hydrogen peroxide-induced oxidative damage in human liver HepG2 cells via induction of heme oxygenase-1. Chem Biol Interact. 2010;183(3):380-9

13. Min H, Zi D, Quan Z. Effects of ferulic acid, senkyunolide $H$ and senkyunolide I on erythrocytes. Lishizhen Medicine \& Materia Medica Research. 2003; 14(12):738-9.

14. Wang $Y H$, Liang $S, X u$ DS, Lin $X$, He CY, Feng $Y$, Hong YL. Effect and mechanism of senkyunolide I as an anti-migraine compound from Ligusticum chuanxiong. J Pharm Pharmacol. 2011;63(2):261-6.

15. Li GS, Ma CJ, Li XY, Liu K. Studies on the Stability of Ligustilide and the Analysis oflts Isomerized Products by GC-MS. Chinese Traditional and Herbal Drugs. 2000;06:7-9.

16. Xiong YK, Liang S, Du Y, Tian F, Feng Y. HPLC determination of equilibrium solubility andapparent oil/water partition coefficient of senkyunolide I. Chinese Journal of Pharmaceutical Analysis. 2012;09:1644-7.

17. Yan R, Lin G, Ko NL, Tam YK. Low oral bioavailability and pharmacokinetics of senkyunolide a, a major bioactive component in Rhizoma Chuanxiong, in the rat. Ther Drug Monit. 2007;29(1):49-56.

18. He CY, Wang S, Feng Y, Liang S, Lin X, Xu DS, Ruan KF. Pharmacokinetics, tissue distribution and metabolism of senkyunolide I, a major bioactive component in Ligusticum chuanxiong Hort. (Umbelliferae). J Ethnopharmacol. 2012;142(3):706-13.

19. Stariat J, Sestak V, Vavrova K, Nobilis M, Kollarova Z, Klimes J, Kalinowski DS, Richardson DR, Kovarikova P. LC-MS/MS identification of the principal in vitro and in vivo phase I metabolites of the novel thiosemicarbazone anti-cancer drug, Bp4eT. Anal Bioanal Chem. 2012;403(1):309-21.

20. Holcapek M, Kolarova L, Nobilis M. High-performance liquid chromatographytandem mass spectrometry in the identification and determination of phase I and phase II drug metabolites. Anal Bioanal Chem. 2008;391(1):59-78.

21. Yang L, Xu S, Liu C, Su Z. In vivo metabolism study of ginsenoside Re in rat using high-performance liquid chromatography coupled with tandem mass spectrometry. Anal Bioanal Chem. 2009;395(5):1441-51.

22. Liu CW, Lu YY, Yang ZZ, Xing YY, Xi T. Rapid screening and characterization of metabolites from a marine-derived actinomycete by high-performance liquid chromatography coupled with electrospray ionization quadrupole time-of-flight mass spectrometry. Rapid communications in mass spectrometry : RCM. 2010;24(23):3413-8.

23. Xiong $Y K$, Lin $X$, Liang $S$, Hong $Y L$, Shen L, Feng $Y$. Identification of senkyunolide I metabolites in rats using ultra performance liquid chromatography/quadrupole-time-of-flight tandem mass spectrometry. J Pharm Biomed Anal. 2013;81-82:178-86.

24. KOBAYASHI M, FUJITA M, MITSUHASHI H. Studies on the constituents of Umbelliferae plants. XV. Constituents of Cnidium officinale: occurrence of pregnenolone, Coniferylferulate and Hydroxyphthalides. Chemical \& Pharmaceutical Bulletin. 1987;35(4):1427-33.

25. TSUCHIDA T, KOBAYASHI M, KANEKO K, MITSUHASHI H. Study on the constituents of Umbelliferae plants. XVI. Isolation and structures of three new ligustilide derivatives from Angelica acutiloba. Chemical \& Pharmaceutical Bulletin. 1987:35(11):4460-4.

26. Cui L, Qiu F, Yao X. Isolation and identification of seven glucuronide conjugates of andrographolide in human urine. Drug metabolism and disposition: the biological fate of chemicals. 2005;33(4):555-62.

27. Garcia-Fuentes M, Trapani A, Alonso MJ. Protection of the peptide glutathione by complex formation with alpha-cyclodextrin: NMR spectroscopic analysis and stability study. European journal of pharmaceutics and biopharmaceutics : official journal of
Arbeitsgemeinschaft fur Pharmazeutische Verfahrenstechnik eV. 2006;64(2): $146-53$.

28. Naito T, Katsuhara T, Niitsu K, Ikeya Y, Okada M, Mitsuhashi H. Two phthalides from Ligusticum chuangxiong. Phytochemistry. 1992;31(2):639-42

29. Bateman TJ, Debenham JS, Madsen-Duggan C, Toupence RB, Walsh TF, Truong Q, Bradley SA, Doss GA, Kumar S, Reddy VB. Glutathione Stransferase catalyzed desulfonylation of a sulfonylfuropyridine. Drug metabolism and disposition: the biological fate of chemicals. 2010; 38(1):108-14.

30. Meech R, Mackenzie PI. Structure and function of uridine diphosphate glucuronosyltransferases. Clinical \& Experimental Pharmacology \& Physiology. 1997;24(12):907-15

31. Armbrecht HJ, Lakshmi VM, Wickstra J, Hsu FF, Zenser TV. Metabolism of a heterocyclic amine colon carcinogen in young and old rats. Drug Metabolism \& Disposition the Biological Fate of Chemicals. 2007: 35(4):633-9.

32. Alexander J, Wallin H, Rossland OJ, Solberg KE, Holme JA, Becher G, Andersson R, Grivas S. Formation of a glutathione conjugate and a semistable transportable glucuronide conjugate of $\mathrm{n} 2$-oxidized species of 2-amino-1-methyl-6-phenylimidazo[4,5-b]pyridine (phip) in rat liver. Carcinogenesis. 1991;12(12):2239-45.

\section{Submit your next manuscript to BioMed Central and we will help you at every step:}

- We accept pre-submission inquiries

- Our selector tool helps you to find the most relevant journal

- We provide round the clock customer support

- Convenient online submission

- Thorough peer review

- Inclusion in PubMed and all major indexing services

- Maximum visibility for your research

Submit your manuscript at www.biomedcentral.com/submit
) Biomed Central 